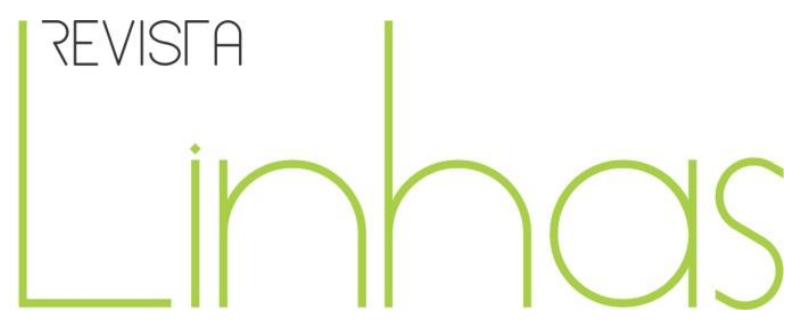

\title{
Jovens e juventudes em contextos rurais: produções científicas da pós-graduação brasileira (2010-2015)
}

\begin{abstract}
Resumo
O artigo objetivou mapear as dissertações de mestrado e teses de doutorado brasileiras sobre Jovens e Juventude com foco na Juventude Rural dos últimos cinco anos. Com o intuito de estabelecer um panorama do "estado da arte" nesse campo de investigação, utilizou-se o Banco de Teses da Capes. A partir da etapa de rastreamento das produções científicas defendidas entre os anos de 2010 e 2015, encontrou-se um total de 319 registros ao considerar as palavras-chave Jovem(s) e Juventude(s). Desconsiderando os trabalhos repetidos na primeira filtragem, encontraram-se 272 registros, que se concentram nos anos de 2011 e 2012. A partir dessa etapa, os trabalhos foram separados pelos contextos (rurais e urbanos), sendo encontrados 73 registros de produções científicas voltadas ao tema central deste artigo, a juventude rural. Percebeu-se que a maioria dos registros está alocada em Programas de Pósgraduação em Educação, mantendo em concordância a educação como temática em destaque nas produções acerca da juventude. Acompanhando o número de registros por universidades, verificou-se a concentração da produção acadêmica nas regiões Sudeste, Nordeste e Sul do país.
\end{abstract}

Palavras-chave: Juventude Rural. Juventude. Pesquisa.

\author{
Aline Barasuol \\ Universidade Federal de Santa \\ Maria - UFSM - Brasil \\ abarasuol@hotmail.com

\section{Sheila Maria Doula} \\ Universidade Federal de Viçosa - \\ UFV - Brasil \\ sheiladoula@gmail.com
}

\section{Amábile Tolio Boessio}

Universidade Federal de Santa

Maria - UFSM - Brasil

amabiletolio@hotmail.com

\footnotetext{
Para citar este artigo:

BARASUOL, Aline; DOULA, Sheila Maria; BOESSIO, Amábile Tolio. Jovens e juventudes em contextos rurais: produções científicas da pós-graduação brasileira (2010-2015). Revista Linhas. Florianópolis, v. 18, n. 37, p. 239-262, maio/ago. 2017.
} 


\title{
Youngsters and youth in rural settings: scientific production of postgraduate studies in Brazil (2010-2015)
}

\begin{abstract}
The article aimed to map the Brazilian dissertations and doctoral theses on Youth focused on rural youth in the past five years. In order to establish an overview of the "state of the art" in this field of research, we used the Digital Records of Theses maintained by the Ministry of Education (Capes). From this screening stage of scientific productions defended between 2010-2015, we found a total of 319 records when considering the keywords Young and Youth. Disregarding the works repeated in this first filtering, 272 records were found, which are concentrated in the years of 2011 and 2012. From this stage on, the registers have been separated by the contexts (rural and urban), and 73 works of scientific production focused on the central theme of this article, rural youth, were found. It was noticed that most records are allocated to Postgraduate programs in Education, keeping education in line as a highlighted theme in the productions about youth. Following the number of records by universities, a concentration of the academic production was found in the Southeast, Northeast and South of the country.
\end{abstract}

Keywords: Rural youth. Youth. Search. 


\section{Introdução}

O debate em torno da temática juvenil tem início quando este segmento passa a ser reconhecido, nos centros urbanos, como um "problema social", ou seja, quando os jovens são vistos como a parcela da sociedade vinculada às rebeldias em relação à normatização social. Autores como Karl Mannheim, Marialice Foracchi e Pierre Bourdieu, a partir da década de 1920, deram início às discussões acerca da juventude como categoria conceitual, caracterizando-a não apenas como uma faixa etária ou ligada a fatores biológicos. Atualmente, o jovem é visto como um novo ator político e social nos diversos contextos em que está inserido, o que vem instigando pesquisadores, em especial os ligados às ciências sociais, a entender o segmento juvenil em interação com os demais segmentos sociais, reconhecendo sua importância como categoria analítica a partir, dentre outros campos do saber, de uma sociologia da juventude.

A temática da juventude nas últimas décadas ganhou importância no Brasil, pois tanto o meio acadêmico quanto as políticas públicas e, ainda, o chamado terceiro setor têm colocado o segmento juvenil como pauta de conhecimento, de ações e intervenções. O hiato existente entre juventude urbana e juventude rural explicita que embora haja um aumento dos estudos e ações, ainda é notória a fragilidade do conhecimento acerca da juventude rural brasileira (CASTRO, 2009).

Pesquisas que utilizam como base o "Estado do Conhecimento" ou "Estado da Arte" envolvendo a juventude brasileira têm trajetória recente no país. Nos anos 1990, Cardoso e Sampaio (1995) publicaram uma bibliografia comentada pioneira sobre a juventude, na qual realizaram um levantamento de livros, teses e artigos com a temática. Nesse trabalho, as autoras apresentam os primeiros estudos dentro da já denominada sociologia da juventude. É destacado o início desses estudos a partir de Mannheim nos anos 1920 quando este observa a juventude por uma perspectiva geracional. Logo em seguida, nos anos 1930, ganham destaque na chamada Escola de Chicago os estudos sobre as gangs urbanas, com forte demarcação racial e a territorialidade como fator fundamental na construção da identidade dos jovens negros pertencentes aos guetos, destacando-se aqui Thraster com a obra "The Gang”. A partir desse momento é que o tema da delinquência juvenil ganha força na Escola de Chicago; as autoras destacam nesse período Martza, autor que propôs uma interpretação dessa delinquência por meio 
das condições das classes sociais baixas, entendendo-a como uma contracultura que rejeita os valores impostos pela classe média.

Dando continuidade, as autoras destacam, nas décadas de 1960 e 1970, o protagonismo juvenil em diversos movimentos sociais - surgimento dos hippies -, e aqui é salientado por elas que se retoma uma percepção genérica de juventude, como no surgimento dos estudos sobre a temática. Ao final da década de 1960, destaca-se o chamado grupo de Birmingham, que orienta os estudos sobre juventude pelo prisma dos consumos de massa, discutindo a posição meramente passiva do jovem. Cabe mencionar que os estudos comentados por Cardoso e Sampaio (1995) foram divididos em cinco grandes temas: Juventude e Educação; Juventude e Trabalho; Cultura Jovem: Atitudes; Comportamentos e valores, e por fim, Juventude: Participação Social, Política e Situação da Juventude no Brasil e no Mundo.

Já em 2002, Sposito publicou um balanço da produção científica sobre a juventude brasileira entre 1980 até 1998 - Juventude e Escolarização - que abrangeu apenas estudos ligados à área da educação. Em outra publicação de um estado da arte, no ano de 2009, a autora analisou a produção científica sobre a juventude na pós-graduação brasileira nas áreas de educação, ciências sociais e serviço social, no período de 1999 até 2006. Esta última pesquisa resultou em dois livros "O Estado da Arte sobre Juventude na Pós-graduação brasileira: Educação, Ciências Sociais e Serviço Social” - Volumes 1 e 2, nos quais em conjunto, analisou um total de 1.293 teses e dissertações sobre juventude, sendo 883 da área da educação, 131 do serviço social, 9 da ciência política, 107 da antropologia e 163 da sociologia. O intuito desse estudo, pela equipe de pesquisadores que o viabilizou, segue no sentido de contribuir para que as discussões sobre o tema da juventude se estruturem e se consolidem, deixando de ser apenas emergente (SPOSITO, 2009).

Cabe expor a sistematização, por eixos temáticos, realizada pela autora: Juventude e Escola; Adolescentes em processos de exclusão social; Jovens Universitários: acesso, formação, experiências e inserção profissional; Jovens, sexualidade e gênero; Jovens e trabalho; Juventude, Mídias e TIC; Os estudos sobre grupos juvenis: presenças e ausências; Estudos sobre jovens na interface com a política; e Estudos históricos sobre a juventude: estado da arte. 
Em outra contribuição, Hayashi, Hayashi e Martinez (2008), ao traçarem um panorama do estado da arte sobre jovens e juventude no período entre 1989 e 2006, destacam "que as produções científicas sobre juventude se enriquecem a partir de fertilizações cruzadas e do diálogo entre a sociologia, a antropologia, a ciência política, a demografia, o direito, o serviço social, a economia, a saúde e a educação”. Para os autores, por esse entrelaçamento é que se pode localizar as metamorfoses "que afetam os jovens no campo educacional, o trabalho e desemprego, da sexualidade, da estrutura familiar, das questões éticas e de gênero" (HAYASHI; HAYASHI; MARTINEZ, 2008, p. 135).

Esses autores mapearam 84 trabalhos considerando os termos "jovens e juventude", e perceberam que houve, a partir de 2000, um crescimento expressivo no número de publicações. Foram pesquisadas ao todo 60 dissertações de mestrado, 23 teses de doutorado e ainda uma tese de livre docência. Em relação à instituição de origem da publicação científica, o maior número concentra-se na Universidade de São Paulo (USP), com 13 trabalhos. Considerando a região do país com maior número de pesquisas, aparecem o Sul e o Sudeste, com 29 instituições ao todo. Ao levar em conta os Programas de Pós-graduação aos quais as pesquisas estão vinculadas, 33 trabalhos se encontram em programas de "Educação" e 16 nos programas de "Sociologia". Em relação à juventude rural, foram encontrados apenas três trabalhos, sendo eles dos seguintes autores: Rosani Marisa Spanevello no ano de 2003, Elisa Guaraná Castro em 2005 e Sirle Brum Oliveira no ano de 2006.

É apenas em 2005 que Wheisheimer publica um mapeamento acerca dos jovens em contextos rurais especificamente. Ao balizar o debate acadêmico sobre a juventude rural no Brasil no período entre 1990 a 2004, o autor alerta que "de 1991 a 2000 houve uma redução de $26 \%$ da população jovem no meio rural. Os processos migratórios respondem pelo esvaziamento e pela masculinização da população rural” (WHEISHEIMER, 2005, p. 7). Para ele, o segmento juvenil em zonas rurais está em uma situação de invisibilidade, o que se configura em uma cruel expressão de exclusão social, pois como exposto pelo autor "esses jovens não se tornam sujeitos de direitos sociais e alvos de políticas públicas, inviabilizando o rompimento da própria condição de exclusão" (WHEISHEIMER, 2005, p. 8). Além disso, o autor afirma que "enquanto eles permanecerem invisíveis ao meio acadêmico e ao sistema político, não sendo socialmente 
reconhecidos como sujeitos de direitos, dificilmente serão incluídos na agenda governamental".

Para realizar o mapeamento, Wheisheimer (2005) baseou-se na análise de resumos de teses, dissertações, livros e artigos publicados em revistas e anais de congressos científicos de diferentes áreas. Foram encontradas duas teses de doutorado, três livros, 18 dissertações de mestrado e 27 artigos publicados em periódicos e anais de congressos científicos. Os anos de 2000 até 2003 foram o auge nas produções científicas encontradas pelo autor. Os estudos se dividem em um total de vinte universidades, destacando-se a UFRGS (Universidade Federal do Rio Grande do Sul) e a UFRRJ (Universidade Federal Rural do Rio de Janeiro), que apresentaram maior volume de trabalhos científicos publicados no período em que o autor realizou a análise. Ao considerar somente as dissertações e as teses, é salientado um equilíbrio entre a UFPB - Universidade Federal da Paraíba (três dissertações); a UFRGS - Universidade Federal do Rio Grande do Sul (duas dissertações); a UFRRJ - Universidade Federal Rural do Rio de Janeiro (uma dissertação e uma tese); a UFSC - Universidade Federal de Santa Catarina (uma dissertação e uma tese); a UFSM - Universidade Federal de Santa Maria (duas dissertações); e a USP Universidade de São Paulo (duas dissertações). O autor verificou que os estudos se concentram nas regiões Sul, Sudeste e Nordeste do Brasil, o que pode ser explicado pela localização de maior número de universidades. Cabe destacar a sistematização elaborada pelo autor e ainda o número de publicações em cada uma: I) Juventude e educação rural - oito publicações; II) Juventude, identidades e ação coletiva - 13 publicações; III) Juventude rural e inserção no trabalho - 10 publicações; e por fim, IV) Juventude e reprodução social na agricultura familiar - 19 publicações.

Além de Wheisheimer (2005), Castro et al. (2009) analisaram materiais bibliográficos (livros, teses de doutorado, dissertações de mestrado e monografias de cursos de especialização, artigos e resumos em revistas e congressos acadêmicocientíficos, capítulos de livros e relatórios de pesquisas nacionais) a respeito da juventude rural e suas variações de expressão (juventude rural, jovem rural, jovens agricultores, jovens filhos de agricultores, jovens do MST, juventude do MST, jovem camponês, juventude camponesa, jovem trabalhador rural, jovem empreendedor rural, jovem 
empresário rural, juventude sem-terra, jovem sem-terra, jovem do interior), delimitando o recorte temporal dessa produção entre 1985 e 2007.

Foi identificado pelas autoras que a partir de 2000 houve um rápido crescimento da produção bibliográfica com esta temática, com uma média de 22 trabalhos por ano, concentrando no ano de 2006 um total de 40 trabalhos. Na produção científica levantada por Castro et al. (2009), há 93 trabalhos entre artigos, capítulos de livros, relatórios de pesquisa e resumos em anais de congressos; 89 registros entre teses, dissertações e monografias (16 teses, 71 dissertações e duas monografias) e 15 livros publicados. Em relação à região de origem das produções, verificou-se grande desigualdade. Percebeu-se que as regiões Sudeste, Sul e Nordeste destacam-se como principais locais de publicação e de produção acadêmica (48,40\% na região Sudeste; $23,40 \%$ na região Sul; $18,09 \%$ na região Nordeste; 9,04\% na região Centro-Oeste; já a região Norte apresentou poucas referências bibliográficas). Assim como nos achados de Wheisheimer (2005), Castro et al. (2009) salientam que as regiões que concentram o maior número de produção acadêmica sobre o tema da juventude rural (Sudeste, Sul e Nordeste) são também aquelas que proporcionalmente têm o maior número de artigos, dissertações de Mestrado e teses de Doutorado, o que pode ser atribuído pelo grande número de universidades com nível de Pós-graduação.

Vale mencionar que, como exposto pelas autoras, as duas regiões onde se têm uma concentração da produção sobre a juventude rural - Sul e Sudeste -, são os locais onde foram produzidas as primeiras dissertações de Mestrado, na Universidade Federal do Rio Grande do Sul (UFRGS) em 1988; na Universidade Federal do Espírito Santo (UFES) no ano de 1990 e na Universidade Federal de Viçosa (UFV) em 1992 e 1993. Já na região Nordeste, foram identificadas produções científicas com o tema apenas em meados da década de 1990, e somente após os anos 2000 nas regiões Centro-Oeste e Norte.

A respeito da principal temática abordada nas produções, Castro et al. (2009) observaram que os estudos de juventude rural são abordados especialmente pelo campo da Educação. De acordo com as autoras, "a área da Educação, na qual se localiza a maior quantidade de trabalhos sobre a juventude rural e programas distintos, foi a pioneira em produzir dissertações de Mestrado e teses de Doutorado. Nela, o tema tem estado sempre presente ao longo dos anos" (CASTRO et al., 2009, p. 54). Castro et al. (2009) 
também mapearam as áreas do conhecimento em que as produções científicas contidas no levantamento bibliográfico estão alocadas: 70,8\% estão nas Ciências Humanas, seguida das Ciências Sociais Aplicadas (10,1\%), Ciências Agrárias (7,9\%), Multidisciplinar (6,7\%) e $\operatorname{outros}(4,5 \%)$.

O panorama aqui exposto indica que a categoria juventude rural no país vem ganhando expressividade nas discussões acadêmicas e tem sido foco de pesquisas de pós-graduação, resultando em dissertações e teses com temáticas variadas. Pela importância de se atualizar os estudos dessa natureza - Estado da Arte - acerca da temática, o presente artigo justifica-se pela falta de mapeamentos de pesquisas mais recentes envolvendo a juventude rural brasileira. Para tanto, objetiva-se mapear as dissertações de mestrado e teses de doutorado brasileiras com foco na Juventude Rural, defendidas entre 2010 e 2015. Redin (2012), ao refletir sobre a juventude rural em um estudo de caso no Rio Grande do Sul, destaca que esta temática ainda carece de atenção, apesar de alguns avanços nos esforços acadêmicos. Com isso, salienta-se aqui que o Estado da Arte possibilita a elaboração de um panorama geral e atualizado das pesquisas e estudos sobre o segmento juvenil rural, a inferência das principais discussões já existentes e, finalmente, um olhar mais atento às temáticas e áreas de conhecimento que ainda não são tão exploradas.

\section{Detalhamento dos procedimentos metodológicos}

“A produção de conhecimento, qualquer que seja o campo do saber, não pode prescindir do esforço sistemático de inventariar e fazer balanço sobre aquilo que foi produzido em determinado período de tempo e área de abrangência" (SPOSITO, 2009, p. 7). O exposto refere-se ao que convencionalmente se nomeia "estado da arte" ou ainda “estado do conhecimento", conforme elucidado por Sposito (2009). De acordo com a autora, estudos dessa natureza "permitem, a partir de recorte temporal definido, conhecer e sistematizar a produção de conhecimento, reconhecer os principais resultados da investigação, identificar temáticas e abordagens dominantes ou emergentes, bem como lacunas e campos inexplorados abertos à pesquisa futura" (SPOSITO, 2009, p. 17). 
Romanowski e Ens (2006) apontam que a realização destes levantamentos contribui na organização da "definição de um campo", colaborando na indicação de sugestões para a área estudada; além disso, as autoras destacam a respeito desses balanços, que "a análise do campo investigativo é fundamental neste tempo de intensas mudanças associadas aos avanços crescentes da ciência e da tecnologia" (ROMANOWSKI; ENS, 2006, p. 39).

Bühler-Niederberger (2010), ao tecer algumas reflexões sobre a sociologia da infância e o estado da arte neste campo de investigação, aponta para uma "nova" perspectiva teórica sobre as crianças, o que acaba por estimular a investigação empírica, pois até então, a sociologia vinha ignorando as discussões a respeito da infância e é por isso que se torna importante essa abordagem metodológica, pois ela permite tais visualizações. Ao contextualizar estudos desse campo sociológico em diferentes países, o autor destacou a relevância do desenvolvimento destes para a análise da sociedade em si e dos seus significados para a sociologia em geral. Nesse sentido, Nascimento, Brancher e Oliveira (2008), ao tratarem historicamente da sociologia da infância, também chamam atenção para essa atual temática enquanto categoria analítica, pois segundo os autores “mesmo a infância constituindo-se em um problema social desde o século XIX, [isso] ainda não foi suficiente para torná-la um problema de investigação científica" (NASCIMENTO; BRANCHER; OLIVEIRA, 2008, p. 5).

Contudo, é relevante destacar os limitantes das pesquisas fundamentadas em estados do conhecimento, uma vez que um banco de dados não caracteriza um retrato fiel da realidade pesquisada, pois há uma demora na atualização dos dados disponibilizados. É por esse motivo que Silva e Carvalho (2014) atentam para a escolha da fonte em que ocorrerá o levantamento das pesquisas, pois é necessário confiabilidade e rigor nas produções científicas publicadas. Ainda em sua pesquisa, as autoras afirmam que

algumas características do estado da arte devem ser observadas ao se desenvolver uma pesquisa com esse método; uma delas é o tempo e o espaço em que os estudos analisados foram desenvolvidos. O recorte temporal e espacial nesse método é necessário porque as análises feitas referem-se a concepções e práticas presentes em determinados contextos sociais, políticos, econômicos, culturais etc. Outra característica é o recorte temático, pois serve para definir e delimitar o 
que se busca mapear, possibilitando aos/às pesquisadores/as ou fazerem análises aprofundadas, ou realizarem um panorama amplo sobre determinados temas. (SILVA; CARVALHO, 2014, p. 349)

Nesse sentido, pela importância e "pelo desafio de conhecer o já construído e produzido para depois buscar o que ainda não foi feito, [...] de dar conta de determinado saber que se avoluma cada vez mais rapidamente e de divulgá-lo para a sociedade" (FERREIRA, 2002, p. 259), é que se pautou nesta opção metodológica no presente artigo, já que é a partir do levantamento das produções científicas que se avalia o conhecimento acumulado acerca de determinada temática.

Com o intuito de elaborar uma pesquisa recente da produção científica na pósgraduação sobre a juventude rural no Brasil, utilizou-se o Banco de Teses da Capes (Coordenação de Aperfeiçoamento de Pessoal de Nível Superior) ${ }^{1}$, uma vez que este banco de dados está vinculado ao Ministério da Educação (MEC), sendo o sistema online oficializado para o depósito das dissertações e teses brasileiras. Destaca-se que a responsabilidade de veracidade das informações cabe aos programas de pós-graduação que fornecem diretamente à CAPES os dados correspondentes das produções científicas defendidas.

Em uma primeira etapa de pesquisa, foram utilizadas na ferramenta de buscas do banco de dados em questão os termos jovem(s) e juventude(s). É válido destacar que os filtros utilizados para o rastreamento na base de dados abrangeram três campos específicos para garantir maior segurança e pertinência nos estudos encontrados, sendo eles: título, palavras-chave e resumos. O mapeamento dos estudos compreende os anos de 2010 a junho de 2015, uma vez que estão disponibilizadas no banco de dados apenas as produções científicas da pós-graduação defendidas a partir de 2010. Neste primeiro passo, foram encontrados 319 registros incluindo pesquisas de mestrado profissional, mestrado acadêmico e doutorado, conforme visualizado na Tabela 1:

\footnotetext{
${ }^{1}$ Disponível em: <http://bancodeteses.capes.gov.br/>.
} 
Tabela 1. Número total de registros encontrados no Banco de teses da Capes por palavra-chave.

\begin{tabular}{cc}
\hline PALAVRA-CHAVE & REGISTROS \\
\hline Jovem & 17 \\
Jovens & 214 \\
Juventude & 79 \\
Juventudes & 9 \\
\hline Total & $\mathbf{3 1 9}$ \\
\hline
\end{tabular}

Fonte: Dados da pesquisa, 2015.

A partir desse primeiro levantamento, percebeu-se a necessidade de uma segunda filtragem das produções encontradas, pois há que se ponderar a repetição de duas ou mais vezes do mesmo trabalho. Nesta segunda etapa de filtragem, encontrou-se um total de 272 registros (Tabela 2), concentrados nos anos de 2011 e 2012. Cabe destacar que embora o recorte temporal perpasse os anos de 2010 a 2015, não foram identificadas produções científicas nos demais anos. Embora não tenham sido visualizadas pesquisas nesses anos, isso não significa a ausência destas, pois há um déficit temporal em relação à atualização no banco de dados.

Tabela 2. Número de dissertações e teses filtradas na segunda etapa da pesquisa.

\begin{tabular}{cc}
\hline DOUTORADO & 49 TESES \\
MESTRADO & 223 DISSERTAÇõES \\
Acadêmico & 212 Dissertações \\
Profissional & 11 Dissertações \\
\hline TOTAL & 272 REGISTROS \\
\hline
\end{tabular}

Fonte: Dados da pesquisa, 2015.

De acordo com o objetivo proposto, o recorte do presente artigo centraliza-se na análise das produções referentes à Juventude Rural. Para tanto, em uma terceira etapa metodológica, se fez necessário separar os trabalhos ligados aos contextos urbanos e rurais. Essa etapa sugere um importante passo da pesquisa, pois possibilita perceber a atual expressividade das produções ligadas ao segmento juvenil rural, uma vez que os 
levantamentos bibliográficos anteriores já retratavam a situação de "invisibilidade" da juventude rural.

Em conformidade, ao visualizar a sistematização dos dados na terceira etapa, foi notada a tendência de manter a disparidade, já que apenas $27 \%$ dos registros encontrados dizem respeito aos jovens em contextos rurais (Tabela 3), enquanto 73\% (199 registros) das produções defendidas referem-se à juventude em contextos urbanos. Deste percentual, o maior número de trabalhos está concentrado nas dissertações (162 registros), 154 delas de mestrado acadêmico e oito de mestrado profissional e ainda foram encontradas, porém em menor número (37 registros), as teses de doutorado. Vale salientar que os dados referentes ao contexto urbano não serão analisados, já que este não é o foco do artigo. No entanto, essas informações são relevantes para constatar que, embora os estudos sobre a juventude rural tenham ganhado expressividade, ainda há um hiato significativo das análises acadêmicas entre jovens de contextos rurais e urbanos.

Tabela 3. Número de dissertações e teses com temática de juventude em contextos rurais.

\begin{tabular}{cc}
\hline DOUTORADO & 12 TESES \\
MESTRADO & 61 DISSERTAÇÕES \\
Acadêmico & 58 Dissertações \\
Profissional & 3 Dissertações \\
\hline TOTAL & 73 REGISTROS \\
\hline
\end{tabular}

Fonte: Dados da pesquisa, 2015.

A partir do total de 73 produções acadêmicas encontradas e relacionadas aos jovens em contextos rurais é que tais informações, em uma quarta etapa, foram sistematizadas e analisadas de acordo com os recortes estipulados - expostos na seção a seguir "Os achados da pesquisa". Como não se pretendia para este artigo uma análise exaustiva do conteúdo completo das produções científicas mapeadas, apoiou-se nos títulos, resumos e palavras-chave construídos pelos autores. Tal recurso se explica por não se ter o intuito de analisar os procedimentos metodológicos nem mesmo os recortes teóricos adotados, o que demandaria outro tipo de pesquisa. 


\section{Os achados da pesquisa}

Nesta seção são apresentados e analisados os 73 registros obtidos dentro do recorte temporal estipulado. Salienta-se que foram encontrados, no ano de 2011 , o total de 37 registros (seis teses de doutorado e 31 dissertações de mestrado acadêmico), e em equilíbrio, no ano de 2012 foram defendidas 36 produções acadêmicas (seis teses de doutorado, 30 dissertações de mestrado acadêmico e ainda três dissertações de mestrado profissional). Como pode ser observado, nesses dois anos há um significativo número de produções científicas defendidas, em especial as dissertações.

A partir da sistematização e análise dos dados pesquisados, foi possível identificar as áreas de conhecimento nas quais se enquadram as produções encontradas. Para tanto, apoiou-se na divisão de avaliação da CAPES, na qual as áreas são agregadas a partir do critério de afinidade, compondo dois níveis. O primeiro diz respeito aos três Colégios (Colégio de Ciências da Vida; Colégio de Ciências Exatas, Tecnológicas e Multidisciplinar; Colégio de Humanidades) e o segundo trata das nove Grandes Áreas (Ciências Agrárias; Ciências Biológicas; Ciências da Saúde; Ciências Exatas e da Terra; Engenharias; Multidisciplinar; Ciências Humanas; Ciências Sociais Aplicadas; Linguística, Letras e Artes).

De acordo com esta classificação, mais de $71 \%$ das produções científicas dos últimos anos enquadram-se no Colégio de Humanidades; aproximadamente $23 \%$ estão ligadas ao Colégio de Ciências da Vida; e cerca de 5\% vinculam-se ao Colégio de Ciências Exatas, Tecnológicas e Multidisciplinar (exclusivamente no campo multidisciplinar). É possível visualizar no Gráfico 1 a divisão das pesquisas, segundo a distribuição da Capes por Grandes Áreas. 
Gráfico 1. Distribuição das produções científicas de acordo com as Grandes Áreas de avaliação da CAPES.

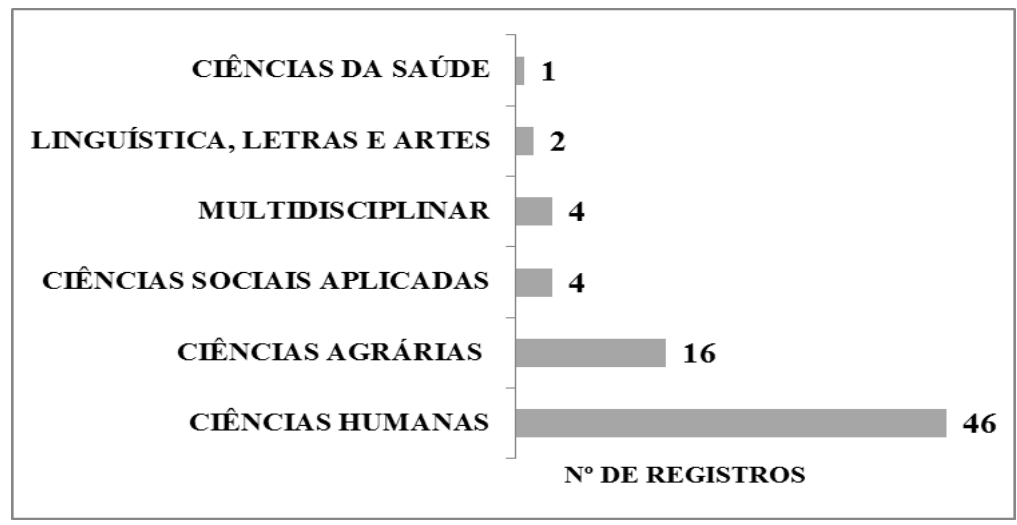

Fonte: Dados da pesquisa, 2015.

Quanto às instituições de nível superior onde foram defendidas as teses e dissertações, estas somam um total de 38 , concentrando-se a maioria na região Sudeste do Brasil (41\%). O Nordeste é a segunda região que mais produz estudos relacionados à juventude rural (26\%), enquanto o Sul aparece como a terceira região com um percentual pouco inferior à segunda (22\%). É possível visualizar na Tabela 4 quais instituições estão produzindo as teses e dissertações, bem como a quantidade de trabalhos defendidos.

Tabela 4. Número de instituições e o total de registros encontrados.

\begin{tabular}{lcc}
\hline \multicolumn{1}{c}{ INSTITUIÇÃO } & REGISTROS & REGIÃO \\
\hline UFV (7); UNESP (4); UNICAMP (3); UFMG (3); USP (2); UFRRJ (2); & 30 & Sudeste \\
UFES (1); PUC-SP (1); PUC-MG (1); Univale (1); UFF (1); UENF (1); & & \\
UFSCAR (1); UERJ (1); UFJF (1) & & Nordeste \\
\hline UFRPE (7); UFPB (2); UNEB (2); UFBA (2); UFRN (2); UFC (1); UFS & 19 & Sul \\
(1); UESC (1); CAIRU (1) & & 16 \\
\hline UFSC (6); UFRGS (3); UEM (2); UFSM (1); UTFPR (1); UFPel (1); & & Centro-Oeste \\
UNISC (1); UNISINOS (1) & 6 & Norte \\
\hline UNB (2); UFG (2); UCDB (1); PUC-GO (1) & 2 & 73 \\
\hline UFAM (1); UFPA (1) & & \\
\hline TOTAL & & \\
\hline
\end{tabular}

Fonte: Dados da pesquisa, 2015. 
Cabe destacar as três instituições que mais produzem estudos nesse campo de investigação, sendo elas: a Universidade Federal de Viçosa - UFV, a Universidade Federal de Santa Catarina - UFSC e a Universidade Federal Rural de Pernambuco - UFRPE (entre seis e sete registros). Ainda com concentração de pesquisas realizadas, aparecem a Universidade Estadual Paulista - UNESP, Universidade Estadual de Campinas - UNICAMP, Universidade Federal de Minas Gerais - UFMG e a Universidade Federal do Rio Grande do Sul (entre três e quatro produções registradas). As demais apresentam entre um e dois registros.

Quanto aos registros de pesquisas, levando em conta a concentração de instituições por estado, destaca-se Minas Gerais com 13 instituições de ensino superior, São Paulo apresenta 11 instituições, Pernambuco e Rio Grande do Sul com sete, Bahia e Santa Cataria aparecem com seis instituições, Rio de Janeiro com cinco, os estados de Goiás e do Paraná com três instituições, Distrito Federal e Rio Grande do Norte apresentam duas instituições e por fim, com apenas uma instituição cada estado: Amazonas, Ceará, Espírito Santo, João Pessoa, Mato Grosso do Sul, Pará, Paraíba e Sergipe.

Há que se mencionar que o maior número de registros se aloca em Programas de Pós-graduação apresentados no Quadro 1, concentrando-se na Educação, seguido da Extensão Rural e Desenvolvimento Local, e da Geografia. Os Programas de Pósgraduação, com dois registros cada, são: Antropologia Social; Desenvolvimento Regional; Educação Agrícola e Psicologia.

Vale destacar que alguns Programas apresentam apenas um registro cada, sendo eles: Agronomia; Artes Cênicas; Ciências Biológicas; Ciências Sociais; Desenvolvimento Humano e Responsabilidade Social; Desenvolvimento Local; Desenvolvimento Rural; Ecologia Humana e Gestão Socioambiental; Economia Doméstica; Educação e Contemporaneidade; Educação Escolar; Educação nas Ciências; Enfermagem; Gestão e Avaliação da Educação Pública; Gestão Integrada do Território; Linguagens e Representações; Políticas Públicas; Psicologia Social; Serviço Social; Sistemas de Produção Agrícola Familiar; e Sociologia Política. 
Quadro 1. Programas de Pós-Graduação e o número de produções encontradas.

\begin{tabular}{|l|c|}
\hline \multicolumn{1}{|c|}{ PROGRAMA DE PÓS-GRADUAÇÃO } & REGISTROS \\
\hline Educação & 18 \\
\hline Extensão Rural e Desenvolvimento Local/Extensão Rural & 12 \\
\hline Geografia & 7 \\
\hline Sociologia & 4 \\
\hline Agroecossistemas & 3 \\
\hline
\end{tabular}

Fonte: Dados da pesquisa, 2015.

A partir da análise dos resumos e da sistematização dos dados encontrados, além de verificar quais regiões são responsáveis pelas produções mapeadas, foi possível referenciar também as regiões estudadas, ou seja, os principais loci de pesquisa das dissertações e teses. Salienta-se que essas regiões coincidem com as regiões de defesa nas quais os Programas de Pós-graduação estão situados. Nesse sentido, destacou-se prioritariamente a Região Sudeste, com 22 registros localizados e o principal foco de estudo dos pesquisadores que realizaram pesquisas nessa região está no estado de Minas Gerais (13 registros). A Região Nordeste aparece na sequência com 21 registros de trabalhos, sendo estes concentrados nos estados de Pernambuco e Bahia, ambos com seis registros. Em destaque aparece ainda a Região Sul, registrando 16 produções e destas, sete foram realizadas no estado do Rio Grande do Sul. Já as Regiões Centro-oeste e Norte aparecem com cinco registros cada, cabendo mencionar que dois registros não especificaram a região de pesquisa em seus resumos.

Outro recorte escolhido para análise consiste na apresentação e discussão das principais abordagens temáticas de dissertações e teses dos últimos cinco anos. É válido esclarecer que na leitura dos resumos identificou-se, em alguns casos, duas ou mais grandes temáticas que alicerçavam as discussões das pesquisas. Dessa forma, elencaramse os temas gerais e dominantes dentro de cada uma, não indicando necessariamente a correlação "uma temática - uma produção científica”. Os eixos temáticos abordados nas pesquisas e elencados a partir das análises foram: Educação, Cultura, projetos e trajetórias de vida, trabalho, reprodução social, gênero, migração/permanência, tecnologias de informação - TICs e protagonismo juvenil, conforme se observa na Tabela 5. Embora não apareçam com tanta expressividade, as temáticas de políticas públicas e 
de extensão, bem como desenvolvimento regional e local também perpassam as teses e dissertações encontradas.

Tabela 5. Temáticas dominantes nos resumos das teses e dissertações.

\begin{tabular}{lc}
\hline TEMÁTICA GERAL/DOMINANTE & FREQUÊNCIA \\
\hline EDUCAÇÃO & 30 \\
CULTURA & 18 \\
PROJETOS E TRAJETÓRIAS & 9 \\
TRABALHO & 9 \\
REPRODUÇÃO SOCIAL & 6 \\
GÊNERO & 4 \\
MIGRAÇÃO JUVENIL & 3 \\
TICS & 3 \\
PROTAGONISMO JUVENIL & 2 \\
\hline
\end{tabular}

Fonte: Dados da pesquisa, 2015.

De acordo com a frequência com que os temas apareceram, observa-se predominantemente o debate acerca da Educação, como já havia sido destacado por Sposito (2002; 2009) ao realizar o estudo com a temática da juventude; dessa forma, observa-se que com a Juventude rural, atualmente, tem prevalecido a persistência da interface temática jovem-educação. Diversas abordagens acabam por ser o foco desse eixo temático, porém as principais análises das produções científicas exprimem as práticas pedagógicas e educativas em contextos escolares voltadas aos jovens rurais devido à condição do(a) jovem como aluno(a). Aqui cabe salientar que há uma mudança nas categorias sociais, pois recentemente há uma maior utilização do termo jovem ao invés de aluno, o que pode explicar também a grande incidência de estudos ligados à juventude dentro do campo educacional.

Destaca-se que dentro dessa temática há um olhar especial para as experiências que envolvem a Pedagogia da Alternância (metodologia que consiste em intercalar um período de permanência em regime de internato na escola e outro em casa, aplicando os conhecimentos com a família), como aparece significativamente nos casos das Escolas Família Agrícola e das Casas Familiares Rurais. Em todos estes estudos percebem-se os 
seguintes questionamentos: qual é o sentido da escola? Qual é a influência da escola na formação do sujeito, bem como nos seus projetos de vida? Essas indagações representam a preocupação, por parte dos pesquisadores, em descrever a realidade e o contexto no qual o jovem está inserido, sendo que ele está recebendo a todo o momento informações que contribuirão na construção de sua identidade. Por esse motivo é que os estudos ligados à instituição escolar, especialmente os que se referem à pedagogia da alternância, se destacam, pois se entende que a organização escolar neste caso propicia ao jovem do campo uma educação específica para seu contexto, ou seja, que prepara a juventude para a vida e o trabalho rural integrando a escola e o meio social do indivíduo.

Além desta discussão pedagógica, ressalta-se a presença tanto do caráter formal quanto informal da educação nas pesquisas analisadas. As produções científicas discutem as diversas influências da escola em seu aspecto formal, no desempenho escolar e nas construções dos projetos futuros dos jovens; ademais são debatidas algumas qualificações informais, possíveis por meio da participação em programas e/ou políticas, além de outros cursos disponibilizados pelos diversos órgãos locais, regionais e/ou estaduais que vão contribuir futuramente na formação do sujeito jovem. Cabe lembrar que sempre atrelada à instituição escola está a instituição família, esta última entendida como peça fundamental na educação do jovem, uma vez que se entende a partir desta instituição a formação básica dos indivíduos.

Um segundo eixo temático com relevante expressividade dentre as dissertações e teses dos últimos cinco anos relaciona-se à cultura. Este debate envolve discussões a respeito do modo de vida rural, das identidades e representações dos sujeitos, bem como do aspecto tradicional que caracteriza esse espaço de vida. Neste sentido, muitas pesquisas abordam a agricultura familiar, o campesinato, as populações tradicionais e de assentamentos, enfim contextos em que a juventude rural está imersa, recriando, reavaliando e relendo o seu modo de ver o mundo. Cabe chamar a atenção para algumas pesquisas que abordam o imaginário social, os significados e sentidos atribuídos ao meio rural, bem como as visões relacionadas ao modo de vida e a compreensão que os sujeitos têm de si mesmos. Nessa perspectiva, como apontado em uma das pesquisas, "a identificação de si como jovem rural está implícita no universo cultural em que os jovens ora abraçam, ora rejeitam" (LIRA, 2012, p. 8). 
Outra temática que solidifica as discussões a respeito da juventude rural refere-se aos projetos e às trajetórias juvenis, em suas diversas variações de nomenclatura (projetos futuros, projetos profissionais, projetos escolares e projetos de vida). Aos projetos de vida são correlacionadas as trajetórias juvenis. Embora não se tenha o mesmo significado conceitualmente, as duas temáticas são praticamente entendidas como sinônimas. Dessa forma, as pesquisas apresentam a diversidade de trajetórias, sejam elas individuais, escolares, profissionais e intergeracionais. Cabe destacar na discussão atrelada a tais temáticas o constante dilema entre ficar ou sair do meio rural. De forma geral, as pesquisas tratam dessa questão de forma articulada com os projetos de vida dos jovens, considerando seus projetos futuros e seus projetos profissionais.

O quarto eixo definido a partir das análises concentra-se na categoria trabalho. Vale salientar que este debate está intimamente ligado à condição de ser jovem rural, uma vez que as pesquisas sugerem o rural delimitado pela atividade agrícola. $O$ trabalho é fator crucial para a migração juvenil, pois este ainda é visto com certo peso negativo ao ser contraposto com outras profissões que estejam vinculadas à vida urbana. A diferenciação exposta ao se tratar da divisão por gênero, nos trabalhos agrícolas, demonstra a dificuldade que as mulheres enfrentam como agricultoras, pois a elas coube a situação de maior invisibilidade, restando apenas a realização dos trabalhos domésticos, fato ainda presente em algumas regiões rurais brasileiras.

Outro eixo refere-se às discussões geracionais. Aparece com expressividade nas produções científicas o problema da reprodução social ligada à sucessão (familiar, hereditária, geracional e dos estabelecimentos familiares). Por sua vez, é importante mencionar que esse eixo não está dissociado dos projetos de vida, da migração, da educação, do trabalho e em alguns casos das questões de gênero, pois todos estes são fatores preponderantes à sucessão. Nas pesquisas encontradas percebeu-se a forte influência do trabalho como fator decisivo na construção dos projetos futuros juvenis; por vezes, os jovens optam por outra atividade no meio urbano, não pelo fato de a atividade agrícola ser penosa ou discriminada, mas principalmente pela falta de incentivo das instituições que atuam no meio em que esses estão inseridos.

É interessante destacar ainda que em apenas duas dissertações e duas teses há uma clara menção às diferenças de gênero, sendo esta a principal temática trabalhada. $O$ 
que cabe dizer ainda é que embora não se tenha um número significativo de produções que debatam fundamentalmente a temática de gênero, há na maioria a diferenciação de sexo nas metodologias das pesquisas em função da amostra populacional escolhida pelos pesquisadores.

Como grande consequência do que se expôs, tem-se a tendência migratória dos jovens rurais, sendo este o sétimo eixo temático. O debate não é recente, mas ainda se percebe o esforço por parte dos pesquisadores em problematizar esse fator, uma vez que os estudos utilizados para reflexão teórica nas produções apontam para o envelhecimento da população rural, bem como para a masculinização desta população em decorrência da saída dos jovens do campo, principalmente em função da migração feminina.

Uma temática recente nas discussões ligadas à juventude rural e visualizada na Tabela 5 refere-se às novas tecnologias de informação (TICs). A inclusão digital é uma questão debatida em três dos estudos encontrados, porém cabe destacar que as principais reflexões estão relacionadas ao acesso a essas tecnologias tanto na escola quanto na vida individual. A última temática evidenciada nos estudos e que também vem ganhando destaque recentemente nas discussões acadêmicas reflete o protagonismo juvenil, a participação dos jovens nas escolas, na comunidade e nos movimentos sociais, bem como na formação política da juventude rural.

Finalmente, ao verificar as palavras-chave, identificou-se que a maioria dos registros apresenta os termos: Juventude(s) (rural(is); contemporânea(s)) e jovens (rurais; adolescentes; remanescentes de quilombo; ribeirinhos quilombolas) que aparecem 45 vezes citadas; e ainda Escolas/escolarização/educação (de jovens e adultos; do campo; popular; rural; profissional) com 33 vezes. Tais termos evidenciam que a maior parte das produções explora o tema da educação nos estudos de juventude rural, o que está de acordo com as temáticas gerais abordadas (TABELA 5) e ainda, com o que já pôde ser observado em relação aos principais Programas de Pós-graduação (QUADRO 1). 


\section{Considerações finais}

O Estado da Arte aqui proposto possibilitou a elaboração de um panorama geral e atualizado das dissertações de mestrado e teses de doutorado sobre o segmento juvenil rural. A pesquisa evidenciou, a partir das etapas de rastreamento e filtragem, 73 registros de produções acadêmicas concentradas nos anos de 2011 e 2012 sendo que a maioria tem como área de origem o campo das Ciências Humanas.

É válido ressaltar os Estados da Arte mencionados ao iniciar este artigo, pois estes já indicavam que a categoria juventude rural vem ganhando expressividade nos programas de pós-graduação, fato verificado pelo aumento tanto das produções acadêmicas quanto científicas. Cabe mencionar novamente que de acordo com o primeiro levantamento focado na juventude rural, Wheisheimer (2005) apresenta a produção acadêmica de 14 anos (1990 a 2004), encontrando 20 registros (duas teses e 18 dissertações). Já Castro et al. (2009), em seu mapeamento dos anos de 1985 a 2007 (22 anos), encontraram 87 produções acadêmicas (16 teses e 71 dissertações).

Esses dados constatam o significativo aumento das produções acadêmicas, ainda mais quando correlacionados aos registros aqui encontrados, pois estes revelam que em apenas dois anos (2011 e 2012) as pesquisas voltadas aos jovens em contextos rurais têm despertado o interesse dos pesquisadores, resultando em 12 teses e 61 dissertações. Salienta-se que este aumento recente das produções pode ser justificado, em parte, pelo aumento dos programas de pós-graduação, mas também em decorrência do aumento de vagas disponíveis nos programas já existentes. Tais dados também indicam que, mesmo ainda existindo o "hiato do conhecimento" entre as juventudes, urbana e rural, há um crescimento dos estudos desta última. Esse fator possibilita um aprofundamento a respeito do segmento juvenil rural brasileiro, bem como aponta a consolidação da juventude como campo de investigação.

Os "estados de conhecimento" anteriores também já evidenciavam nos mapeamentos realizados a relação juventude-educação. Conforme encontrado por Castro et al. (2009) e Wheisheimer (2005) identificou-se aqui claramente o sobressalto da abordagem educacional nos estudos de juventude rural principalmente nas regiões Sudeste, Nordeste e Sul do país. Esse fator justifica-se em parte pela grande 
concentração de registros encontrados especificamente no Programa de Pós-Graduação de Educação.

No entanto, como percebido nas análises deste artigo, há ainda uma fraca expressividade das temáticas relacionadas ao desenvolvimento, às políticas e ao protagonismo juvenil, bem como às novas tecnologias de informação. A incipiência desses eixos temáticos nas dissertações e teses sugere uma gama variada de interfaces temáticas e disciplinares ainda aberta a pesquisas futuras.

A partir da concentração de certas temáticas, principalmente da área de educação, atenta-se para o que ainda não foi explorado nas produções acadêmicas. Nesse sentido, cabe ressaltar o que Anita Brumer revela ao estudar o segmento juvenil em contextos rurais no sul do país, pois segundo a autora é importante se compreender profundamente a realidade na qual o jovem rural está inserido, e isto implica conhecer efetivamente as diversas formas de trabalho, as condições de vida e ainda os aspectos subjetivos envolvidos (BRUMER, 2007).

Nessa perspectiva, abre-se o horizonte de pesquisa sobre a juventude rural nos programas de Pós-graduação brasileiros, pois se direciona o olhar para os assuntos ainda não discutidos, como é o caso da subjetividade dos indivíduos, em especial a subjetividade dos jovens. Entende-se que diversos aspectos estão atrelados à subjetividade e estes exigem um aprofundamento teórico e analítico ainda negligenciado, principalmente ao se refletir sobre as especificidades simbólicas do contexto em que o segmento juvenil está inserido, pois é neste que o jovem vivencia as relações cotidianas e compartilha seus valores e sentimentos.

Por fim, a partir da elaboração deste panorama e ao observar algumas carências em relação às discussões já existentes, considera-se importante a realização de outras pesquisas que deem condições de visualização e conhecimento das realidades atuais no que tange à produção científica brasileira para temáticas específicas, e neste caso a juventude rural. Assim, torna-se relevante recomendar também uma ampliação deste estado da arte sobre juventude rural considerando outros tipos de produções científicas, pois os registros aqui expostos não englobam, por exemplo, publicações em periódicos científicos e eventos relacionados à temática juvenil ou rural. 


\section{Referências}

BRUMER, Anita. A problemática dos jovens na pós-modernidade. In: CARNEIRO, Maria José; CASTRO, Elisa Guaraná de (Orgs.). Juventude rural em perspectiva. Rio de Janeiro: Mauad X, 2007.

BÜHLER-NIEDERBERGER, Doris. Childhood Sociology - Defining the State of the Art and Ensuring Reflection. Current Sociology. Los Angeles: SAGE, v. 58, n. 2, p. 155-164, mar. 2010.

CASTRO, Elisa Guaraná de. Juventude rural no Brasil: Processos de exclusão e a construção de um ator político. Rev. Latinoam. Cienc. Soc. Niñez y juv. Colombia: UManizales, n. 7,v. 1, p. 179-208, 2009.

CASTRO, Elisa Guaraná de et al. Os jovens estão indo embora?: juventude rural e a construção de um ator político. Rio de Janeiro: Mauad X; Seropédica, RJ: EDUR, 2009. Disponível em: < http://www.iicabr.iica.org.br/wp-

content/uploads/2014/03/jovensestaoindoembora.pdf >. Acesso em: 22 abr. 2015.

CAPES - Coordenação de Aperfeiçoamento de Pessoal de Nível Superior - Banco de Teses. Disponível em: <http://bancodeteses.capes.gov.br/>. Acesso em: 22 maio 2015.

CARDOSO, Ruth; SAMPAIO, Helena Santana. Bibliografia sobre a juventude. São Paulo: Edusp, 1995.

FERREIRA, Norma Sandra de Almeida. As pesquisas denominadas "estado da arte". Educação \& Sociedade. Campinas: Unicamp ano XXIII, n. 79, p. 257-272, ago. 2002.

HAYASHI, Maria Cristina; HAYASHI, Carlos Roberto; MARTINEZ, Claudia Maria. Estudos sobre jovens e juventude: diferentes percursos refletidos na produção científica brasileira. Educação, Sociedade \& Culturas. Portugal: CIIE, n² 27, p. 131-154, 2008.

LIRA, Juliana Couto Fazio de Albuquerque. Reconfiguração identitária de jovens rurais como estratégia de inclusão social: a experiência dos agentes de desenvolvimento da comunicação na microrregião da Bacia de Goitá - PE. Pernambuco, 2012. Dissertação (Programa de Pós-Graduação em Extensão Rural e Desenvolvimento Local) - UFRP. Pernambuco, 2012.

NASCIMENTO, Cláudia Terra do; BRANCHER, Vantoir Roberto; OLIVEIRA, Valeska Fortes de. A construção social do conceito de infância: uma tentativa de reconstrução historiográfica. Linhas. Florianópolis: FAED, v. 9, n. 1, p. 04-18, jan./jun. 2008.

REDIN, Ezequiel. Jovem rural em questão. Sociais e Humanas. Santa Maria: UFSM v. 25, n. 1, p. 123-139, jan./jun. 2012. 
ROMANOWSKI, Joana Paulin; ENS, Romilda Teodora. As pesquisas denominadas do tipo "estado da arte" em educação. Diálogo Educ. Curitiba: PUCPR, v. 6, n. 19, p.37-50, set./dez. 2006.

SILVA; Francisca Jocineide da Costa e; CARVALHO; Maria Eulina Pessoa de. O estado da arte das pesquisas educacionais sobre gênero e educação infantil: uma introdução. Recife/PE: $18^{\circ}$ REDOR, nov. 2014. p. 346-362.

SPÓSITO, Marilia Pontes. Considerações em torno do conhecimento sobre juventude e escolarização (1980-1998). Brasília: MEC/Inep/Comped, 2002. Disponível em:

<http://www.emdialogo.uff.br/sites/default/files/juventude_escolarizacao_n7_o.pdf>. Acesso em: 04 abr. 2015.

SPÓSITO, Marilia Pontes. Estado da arte sobre juventude na pós-graduação brasileira: educação, ciências sociais e serviço social (1999-2006). Belo Horizonte: Argvmentvm, 2009. Disponível em: < http://www.emdialogo.uff.br/sites/default/files/EstadoArte-Vol-1LivroVirtual_o.pdf >. Acesso em: 04 abr. 2015.

WEISHEIMER, Nilson. Juventudes rurais: mapa dos estudos recentes. Brasília: Ministério do Desenvolvimento Agrário, 2005.

Universidade do Estado de Santa Catarina - UDESC Programa de Pós-Graduação em Educação - PPGE 